\title{
Overdose of Digoxin Leading to Thrombocytopenia: Exceptional Side Effects: A Case Report
}

\author{
L.K. Mohamed Moulay ${ }^{1 *}$, K.D Amedimelé ${ }^{1}$, G. Gansé ${ }^{1}$, C. Tibou1, N.Charei ${ }^{1}$, M. EL Jamili ${ }^{1}$, D. Benzaroual ${ }^{1}$, S. El \\ Karimi $^{1}$, M. El Hattaoui ${ }^{1}$
}

Department of Cardiology, Mohammed VI University Hospital in Marrakech, BP 2360, Marrakech, Morocco

DOI: $10.36347 /$ simcr.2021.v09i04.027

| Received: 27.02.2021 | Accepted: 16.04.2021 | Published: 27.04.2021

*Corresponding author: L.K. Mohamed Moulay

Abstract

Digoxin is extracted from digitalis and is commonly used in patients with atrial fibrillation and in patients with heart failure. Advanced digitalis intoxication can have a fatal outcome, particularly in patients with underlying cardiac dysfunction (1). Drug-induced thrombocytopenia (DITP), although frequent, remains exceptional in the event of overdose with digoxin. An overdose of Digoxin is usually iatrogenic and mainly leads to cardiac effects but can also cause severe thrombocytopenia. However, this latter complication related to digoxin is "exceptional". The lifelong prognosis does not depend on a hemostasis disorder but rather on a secondary cardiac arrhythmia. We hereby report the observation of a 62- year-old patient followed for a dilated cardiomyopathy with a severe left ventricular dysfunction, and also an atrial fibrillation treated with acenocoumarol and digoxin. She has been admitted to the emergency room due to a partial loss of consciousness associated with dizziness and vomiting. Hence, we will discuss here explanatory approaches to the unresolved mechanism of this undesirable effect, scarcely described in the literature.

Keywords: Digoxin, intoxication, thrombocytopenia.

Copyright $(\mathcal{2 0 2 1}$ The Author(s): This is an open-access article distributed under the terms of the Creative Commons Attribution 4.0 International License (CC BY-NC 4.0) which permits unrestricted use, distribution, and reproduction in any medium for non-commercial use provided the original author and source are credited.

\section{INTRODUCTION}

Drugs are important, sometimes common, culprits of blood dyscrasias, including granulocytosis, anemia, and thrombocytopenia [1]. Digoxin is a cardiac glycoside that is being used as an inotrope like to improve systolic dysfunction in patients with congestive heart failure $(\mathrm{CHF})$. It may improve the quality of life in $\mathrm{CHF}$ patients and the recommended range for the serum digoxin concentration has been reduced over the past decade from $0.8-2.0$ nanogram $/ \mathrm{mL}$ to $0.5-0.9$ nanogram $/ \mathrm{mL}$ [2]. The toxicity of digoxin may result from overdose or from iatrogenic causes, especially if renal function is impaired. The thrombocytopenia induced by digoxin remains exceptional and very little described in the literature. Thrombocytopenia caused by drug dependent antibodies occurs suddenly, is typically severe, is often misdiagnosed and therefore commonly recurrent [3]. It is a recognized side effect of treatment with a wide range of medications. Epidemiologic studies performed in the United State and Europe suggest that about 10 persons per million are affected by drug induced immune thrombocytopenia (DITP) annually [4].
We hereby present a case which illustrates a rare adverse event related to the use of digoxin in a 62 year-old patient followed for heart failure with chronic renal failure discovered during his hospitalization.

\section{CASE Report}

A 62-year-old patient with the following cardiovascular risk factors: age, menopause, hypertension under treatment with losartan; also followed for dilated cardiomyopathy and atrial fibrillation under oral anticoagulant therapy and digoxin $0.25 \mathrm{mg} /$ day for 19 years.

A month before her admission she developed bradycardia at 48 beats $/ \mathrm{min}$ and digoxin was discontinued. One week later, the patient resumed her treatment on her own.

Three weeks later, she was admitted to the emergency room due to an incomplete loss of consciousness following a minimal exertion associated with an asthenia, a sweating, a tinnitus, a dyspnea on exertion, a vomiting and then an epigastralgia. 
L.K. Mohamed Moulay et al., Sch J Med Case Rep, Apr, 2021; 9(4): 404-408

The clinical examination on admission, described out a conscious patient with a respiratory rate at 23 cycles/min, a bradycardia at 34 beats/min, an arterial pressure at $100 / 68 \mathrm{mmHg}$, a saturation at $98 \%$ at the ambient air, regular heart sounds and a systolic murmur at the mitral focal point without signs of heart failure.

Furthermore, the electrocardiogram (EKG) showed a regular bradycardia at 33 beats/min equivalent to a 3rd degree atrioventricular block, a wide QRS at $140 \mathrm{~ms}$ with a left QRS axis and a digitalis cup indicating an overdose of digoxin (Figure 1.). A chest X-ray (Figure 3.) showed a cardiomegaly with a rectilinear left middle arch. Plus, the transthoracic echocardiography. (Figure 4.) showed a left ventricle dilated to $64 \mathrm{~mm}$, a global hypokinesia with a left ventricular systolic function estimated at $35 \%$, a moderate mitral leak by dilation of the annulus, some dilated right chambers, a right ventricle with a preserved systolic function, her pulmonary pressures calculated at 55mmh and a compliant inferior vena cava not dilated.

A laboratory test has been performed and showed (see Table 1). Her platelets had dropped at $16 \times 10^{3} / \mathrm{uL}$, it could be noted that that her platelet count was normal at $130 \times 10^{3} / \mathrm{uL}$. However, a digoxinemia was not established out due to lack of reagent.

The patient was then admitted at the cardiology intensive care unit. Her initial treatment has been consisted of stopping digoxin accompanied with an atropine test whose outcome was negative requiring then a temporary pacing. The patient has also received a transfusion of two red blood cells units as well as the correction of hydroelectrolytic disorders. Given the unavailability of digoxin-specific antibody fragments, we therefore opted to force a diuresis by means of a furosemide syringe pumping. Hemodialysis was not possible; urine output was maintained despite severe renal impairment.

One week later, the evolution was marked by clinical and biological improvement with an absence of recurrence of lipothymia, a disappearance of signs of digoxin overdose such as a 3rd degree atrioventricular, a digitalis cup, an atrial fibrillation at 60 beats/minute on the EkG.

(Figure 2.) and hemoglobin at $9.8 \mathrm{~g} / \mathrm{dl}$. It has been also noted an improvement related to the platelet count that increased to $88,000 / \mathrm{uL}$, the serum calcium to $69 \mathrm{mg} / \mathrm{L}$, and the serum potassium to $3.6 \mathrm{mmol} / \mathrm{L}$ as well as the phosphoremia at $55 \mathrm{U} / \mathrm{L}$. The temporary pacing, for its part, was removed after one week and the patient discharged after two weeks of hospitalization with the indication of an arteriovenous fistula.

One month after discharging, the EKG control still found an atrial fibrillation at 60 beats/min, a hemoglobin at $13 \mathrm{~g} / \mathrm{dL}$ and the platelets at $83,000 / \mathrm{ul}$. Eventually, the digoxin was permanently stopped for this patient and marked in her follow-up diary.

Table-1: Result of laboratory test

\begin{tabular}{|c|c|c|c|}
\hline \multicolumn{2}{|c|}{ Com lete blood count } & \multicolumn{2}{|l|}{ Biochemistry } \\
\hline Hemoglobin & $7.4 \mathrm{~g} / \mathrm{dL}$ & $\mathrm{Na}$ & $129 \mathrm{mmol} / \mathrm{L}$ \\
\hline Hematocrit & $24 \%$ & $\mathrm{~K}$ & $6 \mathrm{mmol} / \mathrm{L}$ \\
\hline Leucocyte count & $5.88 \times 10^{3} / \mathrm{uL}$ & $\mathrm{Cl}$ & $88 \mathrm{mmol} / \mathrm{L}$ \\
\hline Platelet count & $16 \times 10^{3} / \mathrm{uL}$ & Creatinine & $73.6 \mathrm{mg} / \mathrm{L}$ \\
\hline Reticulocyte & $11730 / \mathrm{uL}$ & Urea & $1,99 \mathrm{~g} / \mathrm{L}$ \\
\hline Neutrophils & $4.38 \times 10 \mathrm{U} / \mathrm{L}$ & ALT & $16 \mathrm{U} / \mathrm{L}$ \\
\hline Lymphocytes & $0.52 \times 10 \mathrm{U} / \mathrm{L}$ & AST & $26 \mathrm{U} / \mathrm{L}$ \\
\hline Monocytes & $0.78 \times 10 \mathrm{U} / \mathrm{L}$ & $\mathrm{Ca}^{2+}$ & $58 \mathrm{mg} / \mathrm{L}$ \\
\hline Eosinophils & $0.15 \times 10 \mathrm{U} / \mathrm{L}$ & Phosphor & $75 \mathrm{U} / \mathrm{L}$ \\
\hline \multirow{2}{*}{\multicolumn{2}{|c|}{ Inflammatoy markers }} & Vitamin D & $3.08 \mathrm{ng} / \mathrm{L}$ \\
\hline & & HbA1C & $60 \%$ \\
\hline ESR & $\mathrm{Mm}$ & Albumin & $38 \mathrm{~g} / \mathrm{L}$ \\
\hline CRP & $30 \mathrm{mg} / \mathrm{L}$ & TSH & $1.34 \mathrm{mUI} / \mathrm{L}$ \\
\hline \multicolumn{2}{|l|}{ Serolooy } & Parathormone & $45 \mathrm{pg} / \mathrm{mL}$ \\
\hline & Troponin US & $113 \mathrm{pg} / \mathrm{mL}$ \\
\hline HIV antibody & Negative & LDH & $632 \mathrm{UI} / \mathrm{L}$ \\
\hline Hepatic serology & Negative & Bicarbonates & $13 \mathrm{mmol} / \mathrm{L}$ \\
\hline syphilitic serology & Negative & serum Ferritin & $286 \mathrm{ng} / \mathrm{mL}$ \\
\hline
\end{tabular}


CRP: C. reactive Protein; ESR: Erythrocyte Sedimentation Rate; HIVHuman Immunodeficiency Virus; WBC: White Blood Cell.

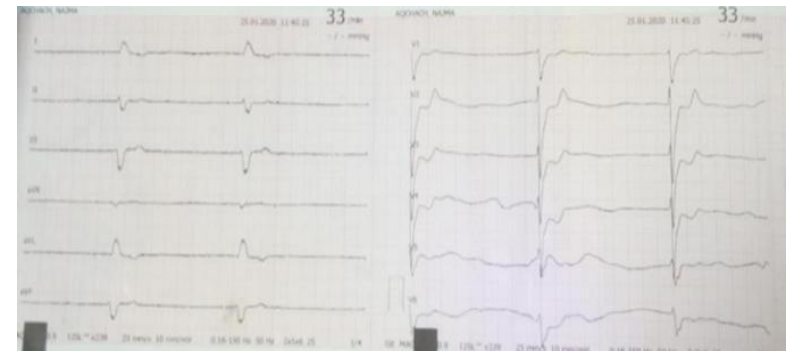

Fig-1:EKG on admission showed a regular bradycardia at 33 beats / min equivalent to a 3rd degree atrioventricular block, a wide $Q R S$ at $140 \mathrm{~ms}$ with a left QRS axis and a digitalis cup indicating an overdose of digoxin

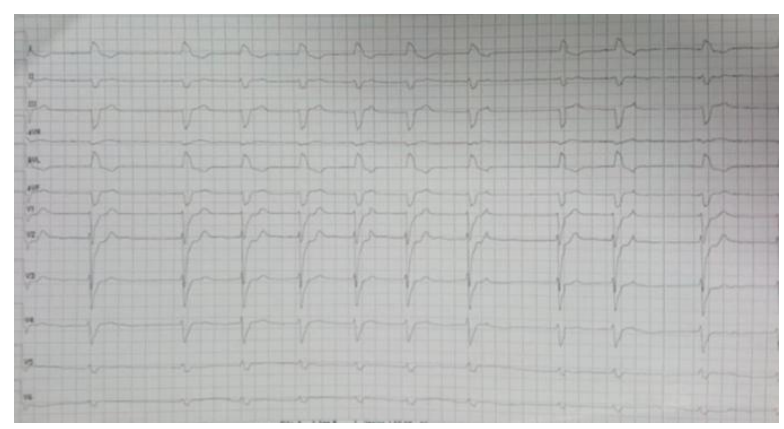

Fig-2: EKG one week later disappearance of signs of digoxin overdose such as a $3^{\text {rd }}$ degree atrioventricular, digitalis cup and atrial fibrillation at 60 beats / minute

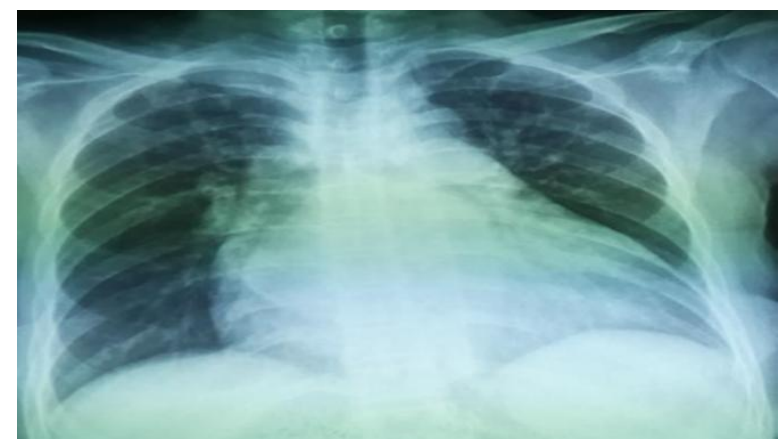

Fig-3: Chest x-ray found cardiomegaly with a rectilinear left middle arch

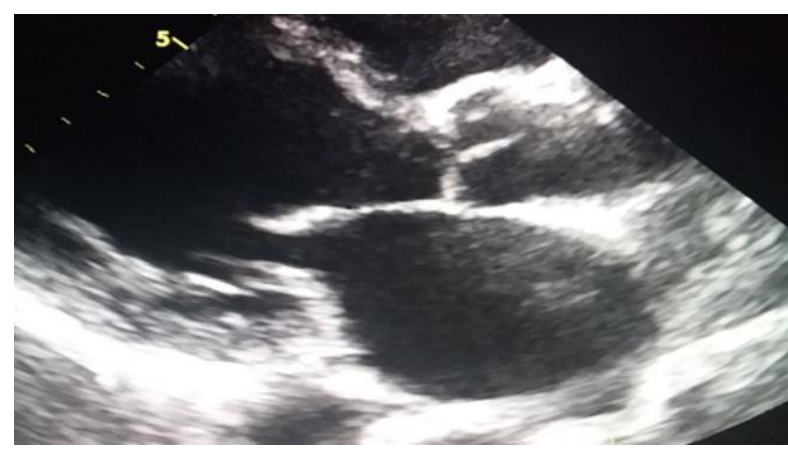

Fig-4: Transthoracic echocardiography in parasternal section long axis

\section{DisCUSSION}

Digitalis toxicity is infrequent but serious drug intoxication. The incidence of digoxin toxicity increases with age, largely because the two most common conditions that benefit from use of digoxin, congestive heart failure and atrial fibrillation, are markedly more prevalent in old age. The elderly are more sensitive to the effects of digoxin because of age; these include a decline in renal function, an increase in the number of comorbid conditions. There are also interactive medications among elderly persons who receive most of the prescriptions than any other population $[5,6]$.

The clinical manifestations of digitalis intoxication are nonspecific and can be conveniently divided into cardiac and non- cardiac effects. It manifests itself most often by gastrointestinal symptoms (nausea, vomiting), ocular symptoms. The cardiac manifestations of toxicity caused by digoxin are characterized by abnormal rhythms and alterations in conduction, but there is no consensus on the relative frequencies of these arrhythmias [7]. As for biological manifestations, renal failure is often found and hyperkalemia is a constant sign of serious intoxication. It is closely linked to the prognosis and it is believed to closely reflect the level of inhibition of the pump membrane $\mathrm{Na} \mathrm{K}$ - ATPase, cell potassium depletion and therefore digitalis impregnation level $[8,9]$.

Digitalis intoxication manifests itself in priority as cardiac effects, but an overdose of digoxin can also lead to severe thrombocytopenia [10]. Among the cardiac glycosides, digitoxin has been most incriminated in some cases as the cause of an immunethrombocytopenia [11, 12]. These cases are mainly reported for female patients of old age. Compared to digoxin which has a shorter half-life than digitoxin, thrombocytopenia induced by digoxin is poorly known; a case of severe thrombocytopenia induced after intravenous administration of digoxin in an 87-year-old woman was described [10].

Based on data found in the literature, the thrombocytopenia induced by digitalis is preferentially described in middle-aged or elderly women, like our case. Thrombocytopenia induced by the toxicity of cardiac glycosides is related to an allergic reaction [13], another patient developed digoxin -induced vasculitis which was associated with positive skin test [14]. This complication of digoxin is, according to Vidal®, "exceptional outside of an overdose". It recently became known that cardiac glycosides modulate the production of various proinflammatory cytokines [15]. The mechanism of occurrence of drug-induced thrombocytopenia has been previously evaluated, implying an inhibition of bone marrow production, platelet consumption or microangiopathy and immunological hyper destruction $[16,17]$. In the case of digoxin, thrombocytopenia may be secondary to peripheral destruction, the pathophysiology of which 
L.K. Mohamed Moulay et al., Sch J Med Case Rep, Apr, 2021; 9(4): 404-408

remains complex and under discussion, in particular due to the fact that in order to create thrombocytopenia, a long-term setting and a therapeutic overdose [18], are necessary, similar to our case. These effects may be particularly relevant in patients with atrial fibrillation for whom digoxin use could exacerbate platelet activation, which is associated with an increased cardiovascular disease incidence [19].

The diagnosis of digitalis overdose is not normally difficult when definite clinical signs are present. In our case the diagnosis was confirmed by extracardiac symptoms (anorexia, nausea, diarrhea and visual disturbances), arrhythmias and toxic blood levels of glycoside. The intoxication had come about through the patient's failure to adhere to his prescribed digoxin dosage. In addition, the patient had severe thrombocytopenia, which is known to occur as a rare complication of digoxin poisoning, even when the glycoside has previously been well tolerated for many years [2]. According to a study published in 2018, in the Journal of American Heart Association, serum digoxin is associated with increased urinary excretion of thromboxane B2 in patients with atrial fibrillation, and in vitro experiments have shown that digoxin increases platelet function in pre-stimulated platelets [19]. There are no evidence-based guidelines for the management of mild to moderate toxicity so there is a wide variation in treatment. The initial step is to assess the severity of the problems and the reason for the development of toxicity should always be thoroughly sought. Severe toxicity (the presence of major dysrhythmias) is clearly potentially life-threatening and carries a high mortality [20]. In these circumstances, a rapid and more aggressive management stratagem must therefore be followed which requires hospital admission and consideration of the need for digoxin- specific antibody fragments. Although digoxin-specific antibody fragments are safe and effective, randomized trials have not been performed. The antibody fragments form complexes with the digoxin molecules. These complexes are then excreted in the urine [2]. Atropine or temporary pacing often used in heart block; phenytoin, beta-blockers and lignocaine are used in malignant ventricular dysrhythmias [20]. In our case, atropine failed to accelerate the heart rate and we do not have an antidote, the management was therefore monitoring, a temporary pacing and correction of hydroelectric disorders.

A decision on whether to discontinue medication in a patient with possible DITP must be based on clinical considerations, as testing for drug dependent antibody requires time and is not widely available. When necessary, pharmacologically equivalent drugs with a different chemical structure can usually be substituted safely for medications essential to a patient's medical care. It is reasonable to give platelet transfusions to severely thrombocytopenic patients who have 'wet purpura, because of their increased risk of intracranial hemorrhage [21].

\section{CONCLUSION}

Thrombocytopenia due to an overdose of digoxin is an exceptional complication. The vital prognosis does not depend on the hemostasis disorder but rather on secondary cardiac arrhythmia. Patients on digoxin should be kept within the therapeutic range of digoxin to avoid not only proarrhythmic side effects but also thrombocytopenia. Practitioners should be able to recognize the clinical manifestations of this clinical presentation, differentiate it from other causes, and manage it appropriately.

\section{Conflict of Interests}

There are no conflicts of interests for the development of this publication.

\section{REFERENCES}

1. Kam T, Alexander M. Drug-Induced Immune Thrombocytopenia. Journal of Pharmacy Practice. oct 2014;27(5):430-9.

2. Pincus M. Management of digoxin toxicity. Aust Prescr. févr 2016;39(1):18-20.

3. Mitta A, Curtis BR, Reese JA, George JN. Druginduced thrombocytopenia: 2019 Update of clinical and laboratory data. American Journal of Hematology. 2019; 94(3):E76-8.

4. Aster RH, Curtis BR, McFARLAND JG, Bougie DW. Drug-induced immune thrombocytopenia: pathogenesis, diagnosis, and management. Journal of Thrombosis and Haemostasis. 2009;7(6):911-8.

5. Wofford JL, Ettinger WH. Risk factors and manifestations of digoxin toxicity in the elderly. The American Journal of Emergency Medicine. mars 1991;9(2):11-5.

6. Kernan WN, Castellsague J, Perlman GD, Ostfeld A. Incidence of hospitalization for digitalis toxicity among elderly Americans. Am J Med. mai 1994; 96(5):426-31.

7. Fisch C, Knoebel SB. Digitalis cardiotoxicity. J Am Coll Cardiol. mai 1985;5(5 Suppl A):91A98A.

8. Bismuth C, Gaultier M, Conso F, Efthymiou ML. Hyperkalemia in acute digitalis poisoning: prognostic significance and therapeutic implications. Clin Toxicol. 1973;6(2):153-62.

9. Lapostolle F, Catineau J, Jabre P, Haouache H, Adnet F. Renal failure and hyperkalaemia in patients with digoxin overdose. Clin Toxicol. 2010;

10. Pangnarind-Heintz V, Protin X, Desideri-Vaillant C, Sapin-Lory J, Rappold J-P, Schimel-Simon A. Thrombocytopenia induced by digoxin overdose. Annales de biologie clinique. mai 2012;70(3):3612.

11. Pirovino M, Ohnhaus EE, von Felten A. Digoxinassociated thrombocytopaenia. Eur J Clin Pharmacol. févr 1981;19(3):205-7. 
L.K. Mohamed Moulay et al., Sch J Med Case Rep, Apr, 2021; 9(4): 404-408

12. Haro T, Shimoike E, Horiuchi T, Maruyama T, Niho Y. Severe Thrombocytopenia Caused by Digitoxin Intoxication in a Patient With Heart Failure Associated With Sjögren's Syndrome. Jpn Circ J. 2000;64(4):309-11.

13. Smith TW, Antman EM, Friedman PL, Blatt CM, Marsh JD. Part III Digitalis glycosides: Mechanisms and manifestations of toxicity. Progress in Cardiovascular Diseases. juill 1984;27(1):21-56.

14. GJ B, MH. G. digoxin- induced vasculatis. Dans: Digitalis allergy. $1972 ; 10: 441-445$.

15. Matsumori A, Igata $\mathrm{H}$, Ono $\mathrm{K}$, Iwasaki A, Miyamoto T, Nishio R. High Doses of Digitalis Increase the Myocardial Production of Proinflammatory Cytokines and Worsen Myocardial Injury in Viral Myocarditis. Jpn Circ J. 1999;63(12):934-40.

16. George JN, Raskob GE, Shah SR, Rizvi MA, Hamilton SA, Osborne S. Drug-induced thrombocytopenia: a systematic review of published case reports [Internet]. Database of Abstracts of Reviews of Effects (DARE): Qualityassessed Reviews [Internet]. Centre for Reviews and Dissemination (UK); 1998 [cité 1 mars 2020]. Disponible https://www.ncbi.nlm.nih.gov/books/NBK67391/
17. Serraj K, Mecili M, Aouni M, Maaouni A, Andrès E. Les thrombopénies médicamenteuses idiosyncrasiques. /data/revues/02488663/v30i10/S024886630900119 2/ [Internet]. 2 oct 2009 [cité 1 mars 2020]; Disponible à: https://www.emconsulte.com/en/article/227379

18. Pastori D, Pignatelli P, Farcomeni A, Cangemi R, Hiatt WR, Bartimoccia S. Urinary 11-dehydrothromboxane B2 is associated with cardiovascular events and mortality in patients with atrial fibrillation. Am Heart J. sept 2015;170(3):490497.e1.

19. Pastori Daniele, Carnevale Roberto, Nocella Cristina, Bartimoccia Simona, Novo Marta, Cammisotto Vittoria. Digoxin and Platelet Activation in Patients With Atrial Fibrillation: In Vivo and In Vitro Study. Journal of the American Heart Association. 20 nov 2018;7(22):e009509.

20. Lip GY, Metcalfe MJ, Dunn FG. Diagnosis and treatment of digoxin toxicity. Postgrad Med J. mai 1993; 69(811):337-9.

21. Crosby WH. Editorial: Wet purpura, dry purpura. JAMA: The Journal of the American Medical Association. 19 mai 1975; 232(7):744-5. 